\title{
A Novel switching pattern of Modified SVPWM for Z-Source Inverter connected to a Multi-Source System
}

\author{
Younes Riache and Essam S Hamdi \\ School of Science, Engineering and Design \\ Teesside University, Middlesbrough, UK \\ Younes.riache@gmail.com \\ e.hamdi@tees.ac.uk
}

\begin{abstract}
In a stand-alone photovoltaic system, the Z-Source inverter presents an efficient alternative to the boost converter and voltage or current-source inverter combination. Replacing the boost converter by the $Z$-Source impedance network enables realisation of the shoot-through states in the three-phase bridge. In this paper, a novel switching pattern incorporating nine shootthrough states is proposed. The shoot-through states are being distributed equally through all the vectors and this yields a reduction in the total harmonic distortion of the output voltages and currents.
\end{abstract}

Index Terms-Z-source inverter (ZSI); modified space vector modulation (SVM); photovoltaic generator; storage system; shoot-through state; switching pattern; total harmonic distortion (THD).

\section{INTRODUCTION}

It has been long established that the maximum ac output voltage of a voltage-source inverter (VSI) is limited to 1.15 times half the dc link voltage, before being over-modulated. Therefore, the VSI topology can only be used as either a stepdown inverter (dc-ac conversion) or a step-up rectifier (ac-dc conversion). Current-source inverters (CSI), where a dc source is connected to a large inductor, always yield ac output voltages that are higher than the dc voltage feeding the inductor. Therefore, a CSI topology acts as a step-up converter (dc-ac) or step-down converter when operating in rectification mode. Unlike the VSI and CSI topologies, a Z-source inverter (ZSI), where an impedance network is connected between the dc source voltage and the three-phase bridge, can operate in both step-up and step-down modes [1].

Photovoltaic power generation is becoming more reliable and cheaper in addition to its free carbon dioxide release. However, there is a fundamental issue restraining the large diffuse of this technology, which is the fluctuation of the irradiance and temperature. As mentioned above, the traditional VSI cannot operate when the input dc voltage is lower than the peak ac voltage. Therefore, the ZSI provides many advantages in photovoltaic applications such as fewer components, high efficiency, larger range of input voltage, interchangeability of the impedance source inverter and reducing the electromagnetic interference noise [1], [2].

For rural electrification, a stand-alone photovoltaic system with a storage system is commonly used, especially in remote areas where a high amount of sunlight is received. Implementing such a system with a three-phase ZSI, instead of a traditional VSI with DC to DC converter, would result in cost reduction and improved efficiency [3]. Fig. 1 illustrates these two different inverter topologies as employed in a stand-alone photovoltaic system.

Of course, the performance (and cost) of a ZSI depends on the control strategy employed. A number of control strategies are reported in literature [4]-[9]. In [4], a control strategy based on the well-known pulse-with modulation (PWM) technique is proposed and evaluated. A simple boost control is proposed and evaluated in [5] and maximum boost control is investigated in [5], [6]. The implementation of a maximum constant boost control for a 9-switch ZSI supplying two induction motors in an Electric Vehicle (EV) application is described in [7]. The proposed topology allows removing the boost converter step in the EV Powertrain [7].
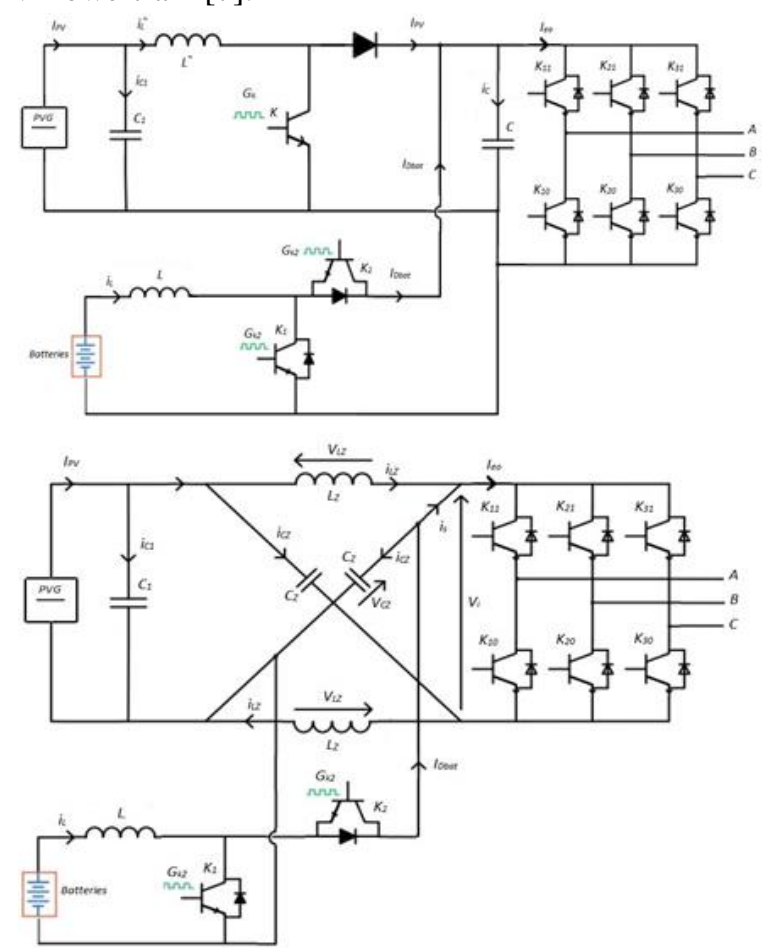

Fig. 1. A conventional VSI with a dc to dc converter (top) and a ZSI converter. 
An alternative control strategy is based on Space Vector Modulation (SVM). In such a strategy, different shoot-through patterns can be implemented to fit the impedance network of the ZSI [8]. These patterns yield lower harmonics content and higher output voltage magnitude compared to pulse-width modulation strategies [8].

Generally speaking, the difference between the various switching patterns is in the number and distribution of the shoot-through states. For example, in [9] six shoot-through states are distributed equally at the beginning and the end of the active vectors. Depending on the shoot-through duty cycle, the previously reported modified SVM strategies have various zero intervals distribution in the switching pattern, which cause oscillation in the inductor current ripple and irregularity application of the shoot-through states [10].

This paper proposes a novel switching pattern of the modified SVM for the Z-source inverter which is incorporated in a new topology of a stand-alone Photovoltaic Generation (PVG). Since this method has the lowest duration of the shootthrough intervals within the switching pattern, the average inverter current flowing through each short-circuited leg of the full-wave bridge is minimised. This yields a decrease of devices' conduction losses and temperature rise. The shootthrough distribution of the proposed switching pattern mitigates the inductor current ripples observed in [9].

\section{PROPOSED SYSTEM}

\section{A. Proposed System Topology}

With reference to Fig. 2, the irradiance and the temperature are the system inputs, which are converted to electrical energy through the photovoltaic generator (PVG Block). These inputs are used by the maximum power point tracker (MPPT) in order to extract maximum power from the PVG [11]. This is done by changing the duration of the shoot-through state in the switching pattern of the control algorithm.

The storage system comprises a battery bank connected to a bidirectional buck-boost converter. This allows the current flow in both direction: towards the ZSI, when the PVG produced energy is less than the load demand, the storage battery systems provides the shortfall. On the other hand, excessive energy is fed to the battery system and stored. The power flow in the proposed system is illustrated in Fig. 4.

The bidirectional converter is responsible for the stability of the DC-rail voltage of the full-wave bridge. The topology presented in Fig. 2 can form a micro-grid due to its ability to regulate the load voltage and frequency.

\section{B. Proposed Switching Pattern}

In the modified SVM, there are seven different shootthrough states, six active vectors and two zero vectors (Z1 and Z2) as defined in [4]. Each state is presented by a vector of six-

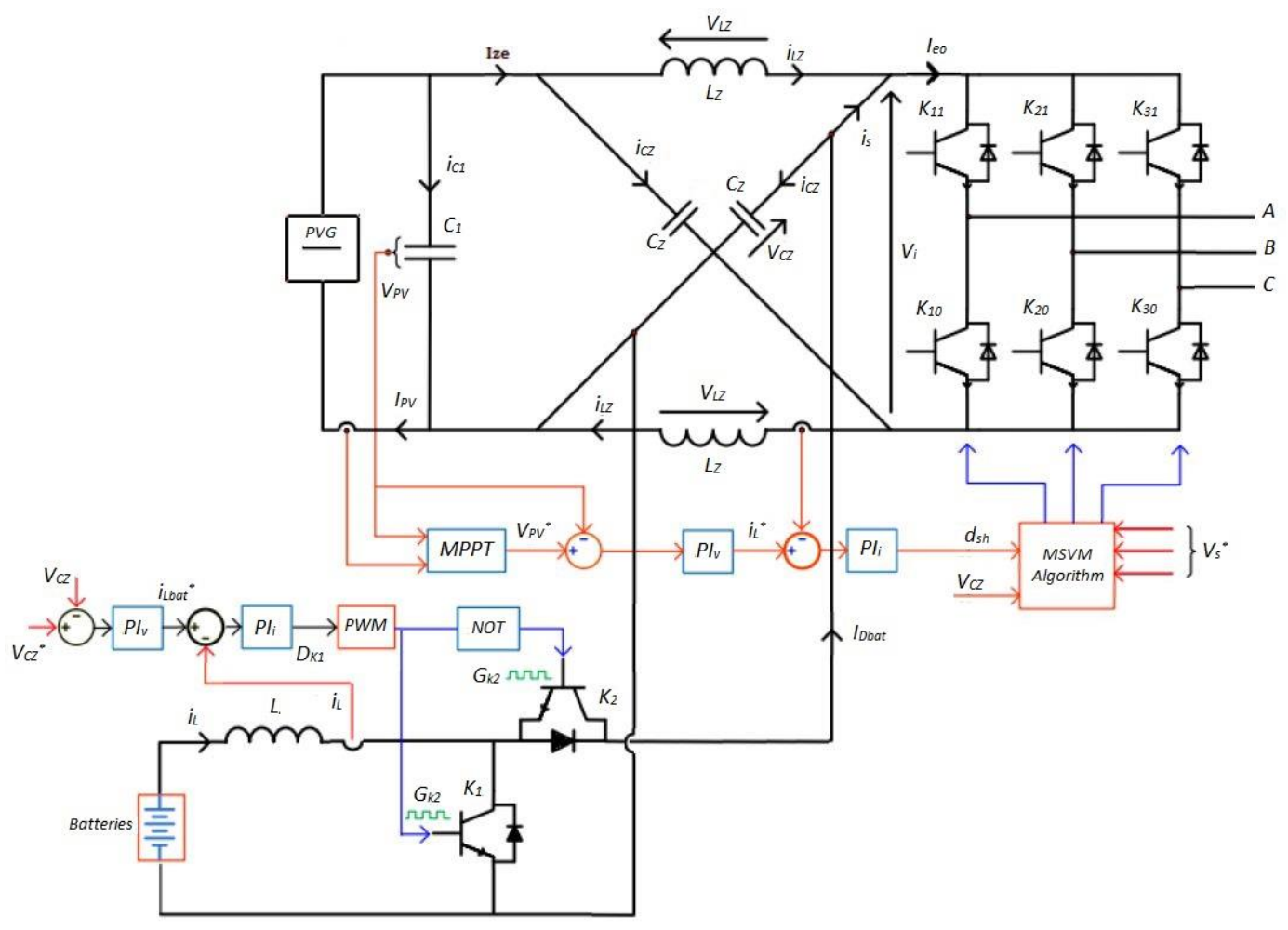

Fig. 2. The proposed system topology.

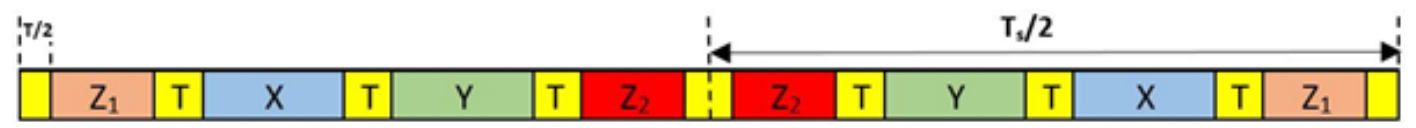

Fig. 3. The proposed switching pattern. 


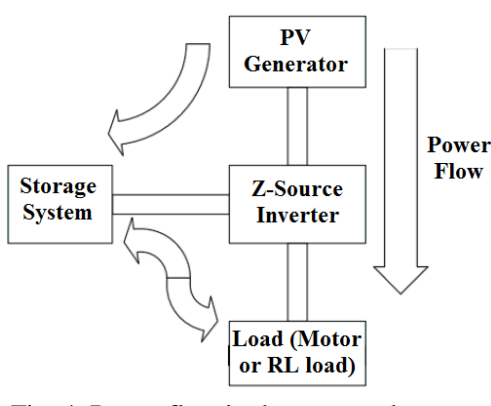

Fig. 4. Power flow in the proposed system.

pulses ( 1 or 0 for each switch). The shoot-through state is chosen each time in a way to minimise the overall number of switching. The goal of the 9 shoot-through states is to reduce the time of shoot-through, which can affect the switches and also produce a symmetric switching pattern.

The shoot-through duration is divided into eight small period, distributed between active and zero states as shown in Fig. 3. It will be shown later (in the results section) that the proposed switching pattern yields less harmonic distortion in the output voltage and current waveforms.

\section{PROPOSED ALGORITHM}

Two possibilities exist for improving the quality of the ZSI output. The first relies on modifying the hardware structure while the second involves implementation of an advanced control strategy. Compared to the traditional PWM methods, Space Vector Modulation produce lower harmonic distortion and boosts the voltage by $15 \%$ [12]. The algorithm inputs are stated below:

\section{A. The desired three-phase voltage vectors}

An LC passive filter is connected between the full-wave bridge of the ZSI and the resistive load as depicted in Fig. 5 so as to hand over a sinusoidal filtered output signals. The doubleloop control explained in [13] are utilised to keep the voltage magnitude and frequency constant irrespective of load.

B. The DC-rail voltage of the full-wave bridge voltage

With reference to Fig. 2, the average value of the discontinuous DC-rail voltage $\left(V_{i}\right)$ is obtained from the voltage $\left(V_{C Z}\right)$ between the conductance $\left(C_{Z}\right)$ and the shoot-through duty ratio $\left(d_{s h}\right)$ with the aid of following the equation [1]:

$$
\bar{V}_{\iota}=\frac{1}{1-d_{s h}} \cdot V_{C Z}
$$

The value of the $\mathrm{Z}$-source capacitance voltage is maintained constant by the loop control of the storage system. A small fluctuation can happen when the inputs of the PV system change, whereas a strong PI regulator is implemented on the bidirectional converter to balance the system.

\section{The shoot-through duty ratio}

The shoot-through duty ratio is responsible for tracking the maximum power point of the PV system. The output current and voltage of the PV system are used by P\&O MPPT

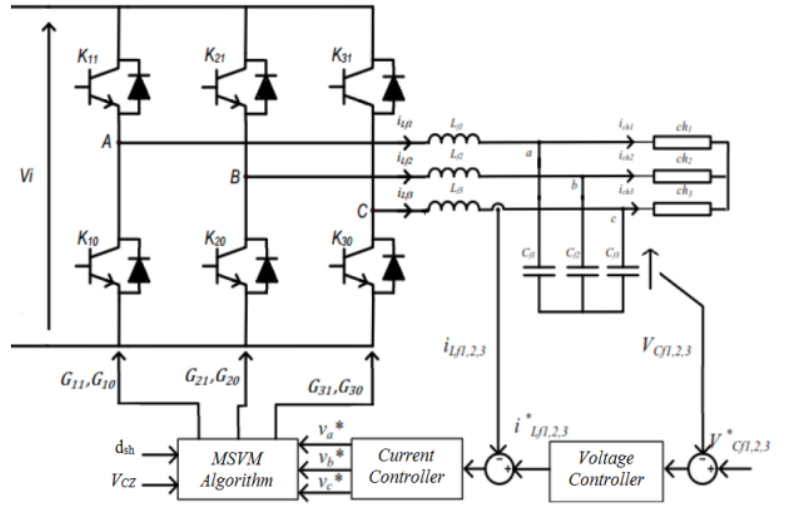

Fig. 5. Control loop of the output voltage and current.

algorithm [14], which hands over the targeted PV voltage. The shoot-through duty cycle is obtained after using the recommended PV voltage in a PI double-loop regulator explained in system configuration part of [15].

\section{Timer}

A timer is used to precisely pick the right switching pattern during the sampling period. When the sampling period is reached, the timer is reset to zero and this is to indicate a new pattern.

After defining the inputs, the first step is the projection of the desired three-phase output voltage on a bidirectional plan and then obtaining the magnitude and the phase of this vector. The magnitude is used to calculate the modulation index and the angle is used to calculate the duration of the active vectors (X and $Y$ ), as is explained in [10]. The duration of the zero vectors $\left(Z_{1}\right.$ and $\left.Z_{2}\right)$, which includes the shoot-through duration, is obtained from the difference between the sampling period and the active vectors duration. Finally, the switching pattern is applied with respect to the time and the thyristors gating pulses are generated.

\section{IMPLEMENTATION AND RESULTS}

In order to assess the performance of the proposed topology and switching pattern, the system is assimilated to a solar PV micro-grid generates an average of $5 \mathrm{~kW}$ in the standard test conditions (STC). Under such conditions, the cell temperature is $25^{\circ} \mathrm{C}$ and the irradiance is $1000 \mathrm{~W} / \mathrm{m}^{2}$ with an air mass 1.5 (AM1.5) spectrum. The PVG is composed from $20 \mathrm{PV}$ SW250-poly panels, which are installed in two parallel groups of 10 panels and required an area of $25 \mathrm{~m}^{2}$. As a result, the rated current and voltage produced are $16.25 \mathrm{~A}$ and $308 \mathrm{~V}$ respectively. Meanwhile, the storage system has a capacity of $5 \mathrm{kAh}$ and a rated voltage of $300 \mathrm{~V}$, which exists in Matlab ${ }^{\circledR}$ library.

The control of the bidirectional buck-boost converter has been done using the PWM with a switching frequency of $5 \mathrm{kHz}$ whereas the sampling frequency of the proposed modified $\mathrm{SVM}$ is $10 \mathrm{kHz}$. In order to reduce the transient phase, the ZSI capacitances should initially be charged. 
The simulation of the complete system is conducted using Simulink of Matlab ${ }^{\circledR}$. Assuming that the load is symmetrical and constant, and the system is running under STC conditions. The proposed scheme performance is compared with the six shoot-through strategy. Simulation parameters are summarised in Table 1.

$$
\text { TABLE I }
$$

SIMULATION DATA

$\begin{array}{lc}\text { Parameter } & \text { Value } \\ \text { Z-Source Inductances }\left(L_{z}\right), \mathrm{mH} & 10 \\ \text { Z-Source Capacitances }\left(C_{z}\right), \mathrm{mF} & 4.7 \\ \text { DC bus voltage }\left(\bar{V}_{l}\right), \mathrm{V} & 622 \\ \text { AC side load resistances, } \Omega & 300 \\ \text { Filter inductances, } \mathrm{mH} & 10 \\ \text { Filter capacitances, } \mu \mathrm{F} & 60 \\ \text { Photovoltaic capacitance, } \mathrm{mF} & 2 \\ \text { Fundamental frequency, } \mathrm{Hz} & 50 \\ \text { Desired output voltage, } \mathrm{V} & 230\end{array}$

The output line and phase voltage waveforms before filtering are shown Fig. 6. The filtered load voltage and current waveforms are shown in Fig. 7.
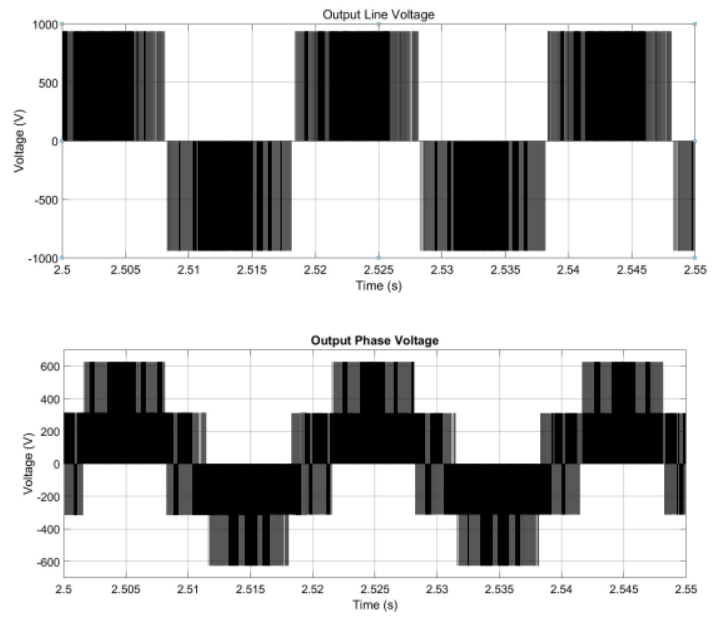

Fig. 6. Simulated output line voltage waveforms before filtering.
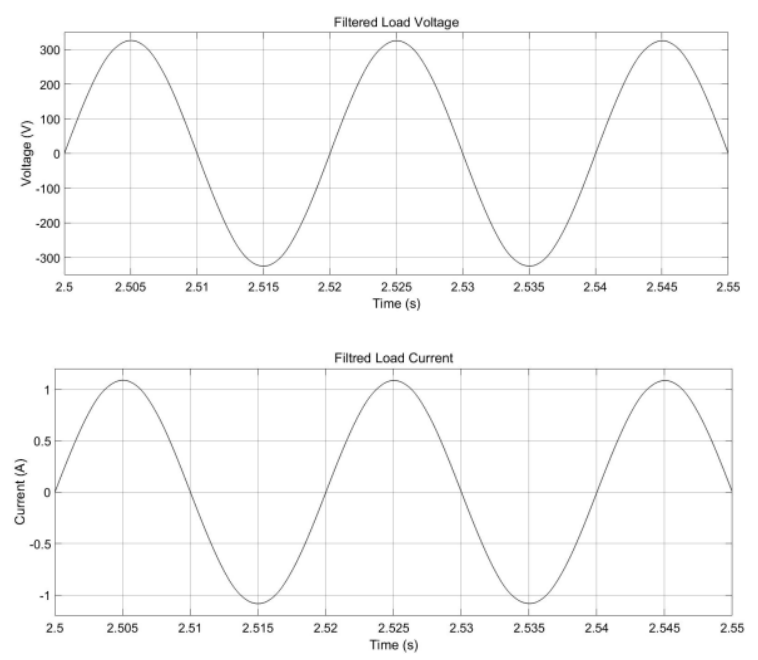

Fig. 7. Simulated load voltage (top) and current waveforms.
In order to quantify the effect of increasing the shootthrough period to nine (compared with previously proposed six shoot- through periods [9]), the output voltage magnitude and harmonic content are investigated. Fig. 8 shows the output voltage frequency spectra using the proposed algorithm and Fig. 9 shows comparable results obtained with six shootthrough periods.

It is seen that the proposed switching strategy yields a fundamental voltage (at $50 \mathrm{~Hz}$ ) of $324 \mathrm{~V}$ compared to $309 \mathrm{~V}$ obtained by implementing previously proposed switching strategy. Also, the nine shoot-through strategy yields a lower THD $(4.1 \%$ compared to $5.48 \%)$.

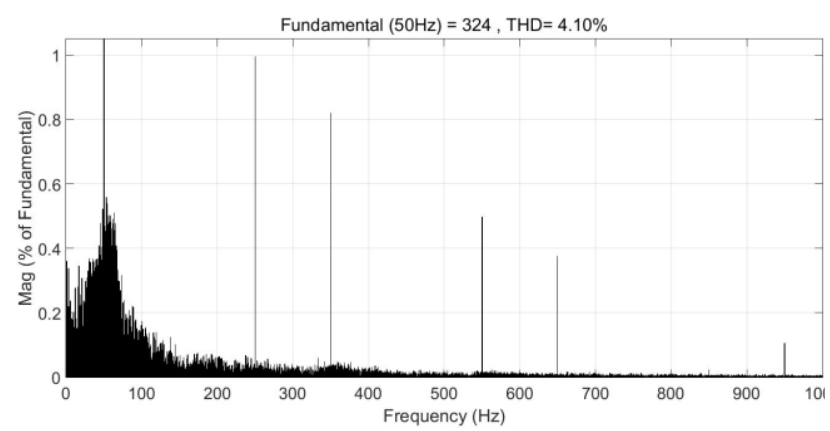

Fig. 8. Output voltage frequency spectra using the proposed switching pattern.

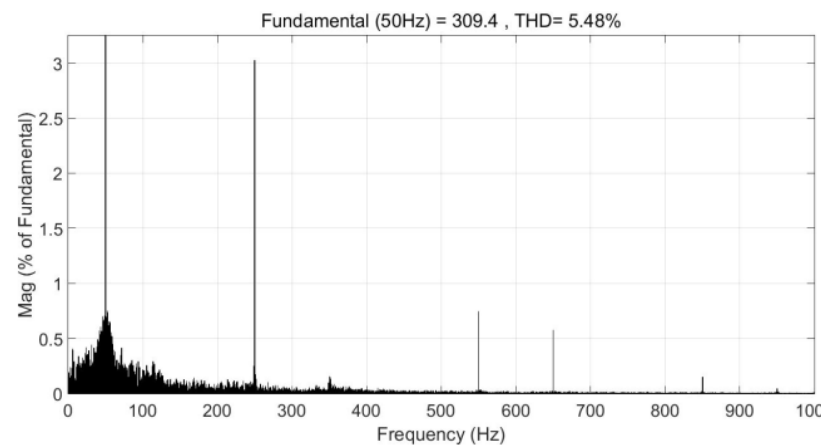

Fig. 9. Output voltage frequency spectra using the modified SVM with 6 shoot-through periods.

\section{CONCLUSIONS}

A Novel switching pattern of modified SVPWM for ZSI connected to a multi-Source System is proposed and evaluated with the aid of Matlab ${ }^{\circledR} /$ Simulink simulation. The proposed 9 shoot-through pattern has been shown to generate less harmonic distortion in the output voltage and current and to provide more efficient use of supply voltage compared to all the previously proposed control methods.

\section{REFERENCES}

[1] F.Z. Peng, "Z-source inverter," IEEE Trans. Ind. Appl., vol. 39, no. 2, pp. 504-510, Mar/Apr. 2003.

[2] Y. Li, J. Anderson, F.Z. Peng and D. Liu, "Quasi-Z-source inverter for photovoltaic power generation systems," $24^{\text {th }}$ Annual IEE Applied Power Electronics Conf. and Exposition (APEC 2009), pp. 918-924, 2009.

[3] R. Badin, Y. Huang, F. Z. Peng and H. Kim "Grid interconnected Zsource PV system," IEEE Power Electronics Specialists Conf., pp. 23282333, 2007. 
[4] P.C. Loh, D. M. Vilathgamuwa, Y. S. Lai, G. T. Chua and Y. Li, "PulseWidth Modulation of Z-Source Inverters," IEEE Trans. Power Electr., vol. 20, no. 6, pp. 1346-1355, Nov. 2005.

[5] M. Shen, J. Wang, A. Joseph, F.Z. Peng, L.M. Tolbert and D.J. Adams, "Constant boost control of the Z-source inverter to minimize current ripple and voltage stress," IEEE Trans. Power Electr., vol. 22, no. 2, pp. 498-507, Mar. 2007.

[6] F.Z. Peng, M. Shen and Z.Qian, "Maximum boost control of the Z-source inverter," IEEE Trans. Power Electr., vol. 20, no. 4, pp. 833-838, Jul. 2005.

[7] M. Shen, J. Wang, A. Joseph, F.Z. Peng, L.M. Tolbert and D.J. Adams, "Maximum constant boost control of the Z-source inverter," IEEE Ind. Appl. Conf., Oct. 2004.

[8] Y. Liu, B. Ge, H. Abu-Rub and F.Z. Peng, "Overview of Space Vector Modulations for Three-Phase Z-Source/Quasi-Z-Source Inverters," IEEE Trans. Power Electr., vol. 29, no. 4, pp. 2098-2108, Jun. 2013.

[9] Y. Liu, B. Ge and H. Abu-Rub, "Theoretical and experimental evaluation of four space vector modulations applied to quasi-Z-source inverters," IET Power Electr., vol. 6, no. 7, pp. 1257-1269, Sep. 2013.

[10] M. Abarzadeh, H.F. Kivi and H.M. Kojabadi, "A modified SVM switching pattern for Z-source inverter," IEEE Power Electronics and Drive Systems technologies Conf., Feb. 2016.
[11] S.E. Babaa, M. Armstrong and V. Pickert, "Overview of Maximum Power Point Tracking Control Methods for PV Systems," Journal of Power and Energy Engineering, no. 2, pp. 59-72, Aug. 2014.

[12] U.S. Ali and V. Kamaraj, "A modified space vector PWM for Bidirectional Z-source inverter," IEEE Emerging Trends in Electrical and Computer Technology (ICETECT) conf., Mar. 2011.

[13] P.C. Loh and D.G. Holmes, " Analysis of multiloop control strategies for LC/CL/LCL-filtered voltage-source and current-source inverters," IEEE Trans. Ind. Appl., vol. 41, no. 2, pp. 644-654, Mar/Apr. 2005.

[14] A.K. Abdelsalam, A.M. Massoud, S.Ahmed and P.N. Enjeti, " HighPerformance Adaptive Perturb and Observe MPPT Technique for Photovoltaic-Based Microgrids," IEEE Trans. Ind. Appl., vol. 26, no. 4, pp. 1010-1021, Apr. 2011.

[15] O. Ellabban, J.V. Mierlo and P. Lataire, "A comparative study of different control techniques for an induction motor fed by a Z-source inverter for electric vehicles," IEEE Power Engineering, Energy and Electrical Drives (POWERENG) Conf., May 2011. 